\title{
Human Resource Information System (HRIS): Important Element of Current Scenario
}

\author{
Barkha Gupta \\ (UGC-NET/MBA-HR/PGDCA/Bsc.(Microbiology)) BHOPAL,(M.P.), INDIA
}

\begin{abstract}
An HRIS, which is also known as a human resource information system or human resource management system (HRMS), is basically an intersection of human resources and information technology through a HR software solution. This allows HR activities and processes to occur electronically. The Human Resource Information System (HRIS) is a software or online solution for the data entry, data tracking, and data information needs of the Human Resources, payroll, management, and accounting functions within a business. The goal of HRIS is to merge the different parts of human resource, including payroll, labor productivity, and benefit management into a less capital intensive system than the mainframes used to manage activities in the past. Also called Human Resource Management systems (HRMS). A HRIS generally should provide the capability to more effectively plan, control and manage HR costs; achieve improved efficiency and quality in $H R$ decision making; and improve employee and managerial productivity and effectiveness. In most situations, an HRIS will also lead to increases in efficiency when it comes to making decisions in HR. This research paper helps to know about how HRIS help the organization to enhance the efficiency of work.
\end{abstract}

Keywords- HRIS, HRM, HRMS, Human Resource, Human Resource Information system

\section{Introduction}

In the ever-changing world in which we live, new technology is continually being developed. This change requires organizational leaders to be cognizant of the different types of technology which could improve the organizational effectiveness. Human Resource Information Systems (HRIS) have drastically evolved since they were first introduced more than 50 years ago - they have gone far beyond their original purposes of converting paper records into computerized databases. In modern times, HR/payroll systems are able to handle several of HR's numerous functions. HR Software is now full of features and self-contained-not just the data storage systems we once knew them as. The developed HRIS will help the organization to effectively store employee data more securely and accurately. Modern HRIS systems are now tools that HR Professionals can use on a daily-basis for several purposes. In the past, companies were used to tracking data on paper and spreadsheets. However, with technological advancements many companies have realized the need to implement more sophisticated computerized systems, like Human Resource Information Systems. By moving to HRIS, companies are able to keep more accurate and up-to-date records, allowing them to better prepare for future growth in their companies. In most situations, an HRIS will also lead to increases in efficiency when it comes to making decisions in HR. The decisions made should also increase in quality - and as a result, the productivity of both employees and manages should increase and become more effective.

\section{Definition}

According to Hedrickson, 2003, "HRIS can be briefly defined as integrated systems used to gather, store and analyze information regarding an organization's human resources."

According to Tannenbaum 1990, "HRIS ,One which is used to acquire, store, manipulate, analyze, retrieve and distribute information about an organization's human resources."

\section{Objectives Of The Study}

$>$ To know about human resource information system.

$>$ To know about uses of HRIS in company.

$>$ To know about how computerized HRIS is more effective than manual system.

$>$ To know about how enhance the ability of the human resource management to leverage and absorb new and emerging opportunities and challenges in the business horizons. 


\section{Literature Review}

\section{IV.1 HR INFORMATION SYSTEM-}

HR Information System is an information system, which is basically used to track data relating to HR. It is one of the Management Information Systems. There has been a lot of change as to how employee data were stored before compared to present systems used in organization. It integrates information like employee details, pay roll, benefits, performance tracking and appraisal etc. Technological advancement led to a lot of changes in HR Management. The storage of data was now shifted from manual ledgers and books to computer hard drives and magnetic tapes. Storage of data became easier and a lot of manual work was removed. HR Management was later seen as a strategic building platform which dealt with the most important resource of any organization. Hence it came to be known as Strategic HR Management (SHRM). The HR Management had total make over when HR Information System was brought into implementation.

\section{IV.2 TRADITIONAL VIEW OF HRIS-}

HRIS is designed to supply information required for effective management of the organization i.e. for decision making relating to human resource. Human resource departments hold the record of the employees of the organization including personal history, skills and salary etc. The basic level of HRIS is used to help to manage employment relationships within the organization and employees. In previously Companies were used to tracking data on paper and spreadsheets and its take time to manage record properly and its time consuming too.Typical HRIS Record employee information, wage and salary data, review dates, benefits, education and training, attendance, performance data,/ appraisal results etc.

\section{IV.3 MORDEN VIEWS HRIS-}

Leading management thinker suggest that ,"it is not technology, but the art of human and humanmanagement." That is the continuing challenges for executive in the $21^{\text {st }}$ century. (Drucker ,dyson, Handy, saffo,\&Senge 1997). Similarly, Smith and kelly1997 believe that" future economic and strategic advantages will rest with the organization that can most effectively attract, develop and retain a diverse group of the best and the brightest human talent in the Market place. The effective management of the human resource in the firm to gain a competitive advantage in the market place requires timely and accurate information on current employees and potential employees in the labor market. With the evaluation of computer technology ,meeting this information requirement has been greatly enhanced through the creation of HRIS. With technological advancements many companies have realized the need to implement more sophisticated computerized systems, like Human Resource Information Systems. By moving to HRIS, companies are able to keep more accurate and up-to-date records, allowing them to better prepare for future growth in their companies. A computerized HRIS is designed to monitor, control and influence the movement of people from the time they join the organization till the time they leave it. Human resource information systems are built to reduce the manual work of HR expertise. HRIS helps to abandon paper forms or reports because all information is available through the system.

\section{Evaluation And Development Of HRIS}

In the early development of human resource management, information systems, although often accurate and comprehensive, were mainly used for administrative and operational purposes. Forms were used to collect leave requests, workers compensation and accident data, and salary variation and superannuation entitlements. During the 1945 and 1960 only manual work is done for manage all HR activities in organization, they have human capital issues, employees morale and formal selection and development method is earlier organization not so much focus on HR related activities they was not taking interest in HR main function. Then early 1960 to 1970 personnel become change into human resource organization was focus on human resource. Human Resource was seen as key in organization. In this time HRIS was used mostly for keeping administrative records.1970s and 1980s, several factors radically changed attitudes towards human resource information systems. After that from 1980 to current large and small business organization are utilizing HRIS. The increasing complexity of payroll systems in this period demanded more flexibility in, and access to information system. Personal computers have made HRIS available and affordable for any sized firm. HRIS has evolved from simple record-keeping to complex analytical tools to assist management decision making. Then according to globalization and technological change computerize HRIS was developed in it system seeks to merge the activities associated with human resource management (HRM) and information technology (IT) into one common database through the use of enterprise resource planning (ERP) software. The goal of HRIS is to merge the different parts of human resources, including payroll, labor productivity, and benefit management into a less capital- intensive system than the mainframes used to manage activities in the past. HRIS also called Human Resource Management System (HRMS).Organizations, centralized payroll processing sections began to be separated from other human resource functions. Some organizations contracted their payroll responsibilities to 
external payroll bureaus with greater technological expertise, and for reduced costs. now many software use in the organization according to their needs and want.

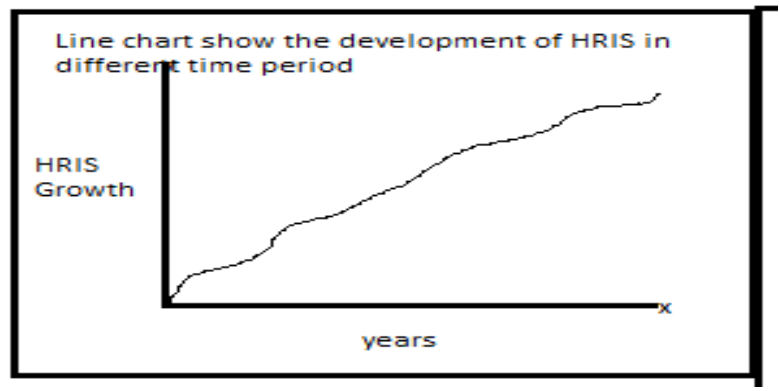

V.1 DEVELOPING AN HRIS: SYSTEM DEVELOPMENT LIFE CYCLE (SDLC)

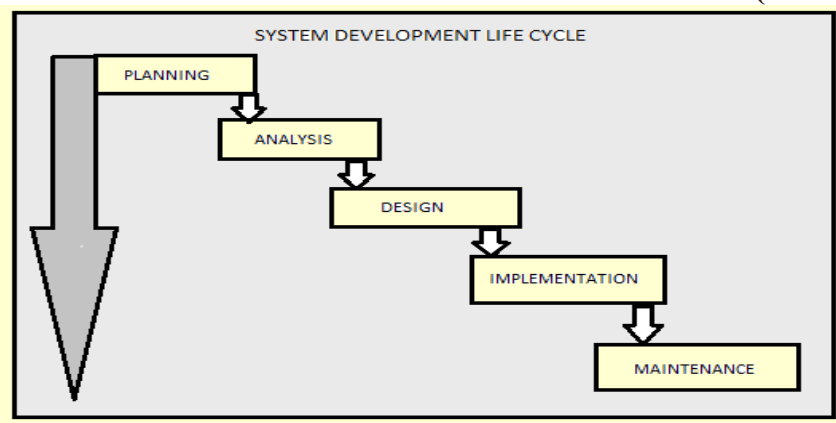

Figure 2

In every organization the person who involve for HRIS development they apply these steps and then work on HRIS.

\section{Role Of HRIS In Companies In Current Scenario}

HRIS help a firm maximize the use of human resource and maintain competitiveness in its market. In most large organizations, human resource information systems (HRISs) provide the technology backbone supporting the complete body of human resource (HR) functions. In this role, HRISs play a critical part in the operation of each component of HR. Additionally, by integrating across business processes HRISs provide organizations with control, forecasting, and planning tools that supersede simple computerization of HR functions. For these reasons, effective use of HRISs in organizations contributes to overall organizational effectiveness. Human Resource Information System is a set of people, forms, procedures and data utilized to store, analyze, distribute and use information of human resources. HRIS goal is to provide accurate information for the use of persons making human resource related decisions. The organization can use HRIS for human resource planning. New recruitments can be posted via HRIS as well as applications can be scanned and stored. HRIS also stores information about the employees' participated trainings and learning sessions. Performance appraisal, compensation, benefits, competences and development plans are easily maintained in HRIS. Employees can search for a new career within the organization and be aware of the future trainings. HRIS allows managers to follow employee's' job performance and planned versus used hours for a certain assignment. HRIS offers various reports available. Typical HR program involve things such as record keeping, recruiting, selection, training, employees retention and compensation.

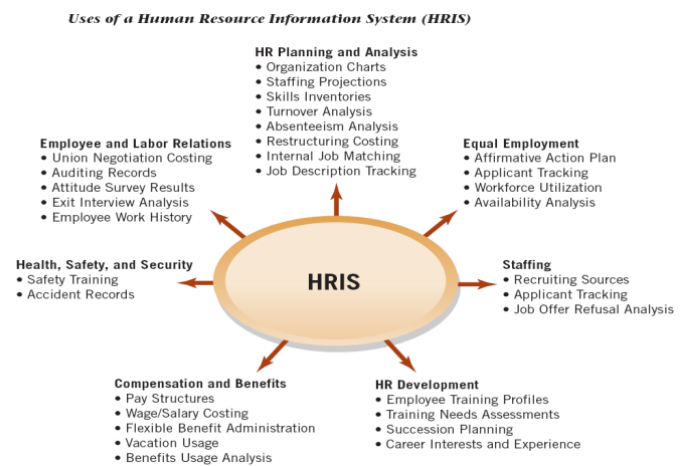

Figure 3 
All this program involve multiple activities and these HR activities can be classified into three broad categories : transactional, traditional and transformational (Wright, Mc Mahan, snell,\& Gerhart, 1998) transactional activities involve day to day transactions that have to deal mostly with record keeping- for example entering payroll information, employees status changes, and the administration of employee benefits. Traditional activities involve HR program such as planning, recruiting, selection, training, compensation and performance management. These activities can have strategic value for the organization, if their results and outcomes are consistent with the strategic goals of the organization. Transformational activities that add value to the organization- for example cultural or organizational change, structural realignment, strategic redirection and increasing innovation.

Table and Pie chart show the HR department activities

\begin{tabular}{|l|l|}
\hline HR Department Activities & Percentage \\
\hline Transactional & $65-75$ \\
\hline Traditional & $15-30$ \\
\hline Transformational & $5-15$ \\
\hline
\end{tabular}

Figure 4

Wright et al. (1998) estimate that most HR departments spent approximately $65 \%$ to $75 \%$ on transactional activities, $15 \%$ to $30 \%$ on traditional activities and $5 \%$ to $15 \%$ on transformational activities. One of the major advantages of design, development and implementation of an HRIS is reduce the amount of time the HR staff.

Some common human resource information systems are:

Performance appraisal: This system analyzes employee performance on the job.

Skills inventory: This system keeps track of employee skills and matches employees with specific jobs.

Benefits administration: This system manages employee fringe benefit packages

Job applicant tracking: This system keeps track of applicants for jobs with the business.

\section{Benefits Of HRIS In Companies}

An effective HRIS provides information on just about anything the company needs to track and analyze about employees, former employees, and applicants. The company will need to select a Human Resources Information System and customize it to meet according to company needs. Comprehensive and integrated HRIS can be used widely - in administrative, operational and strategic fields by HR and other managers. On the operational level HRIS data can be used to identify potential internal applicants for job vacancies, saying external recruitment costs and assuring employees of career opportunities. HRIS enables the human resource department to make a more active role in organizational planning. Computerization will make forecasting more timely, cost effective, and efficient. With continued technological breakthroughs HRIS systems are becoming increasingly advanced. One of the most core HRIS functions is intranet HR self-service. Some larger companies use their intranet today for online appraisals, career management, sentiment surveys, training registrations and publishing people related company information. An HRIS or HRMS monitored by qualified specialists who know technology and HR functional and tactical processes can manage compliance with federal and state laws, streamline processes for recruitment and selection, and produce analyses, data and reports for internal and external use. Other advantages of an HRIS include the ease of use for qualification computer technology specialists, accuracy of information and the ability to perform HR audits using any combination of parameters. The employee and manager self-service features are excellent ways to free up the time of your human resources staff members for project work and other duties. Employees and managers can locate answers and information quickly without the need to consult an HR representative every time.

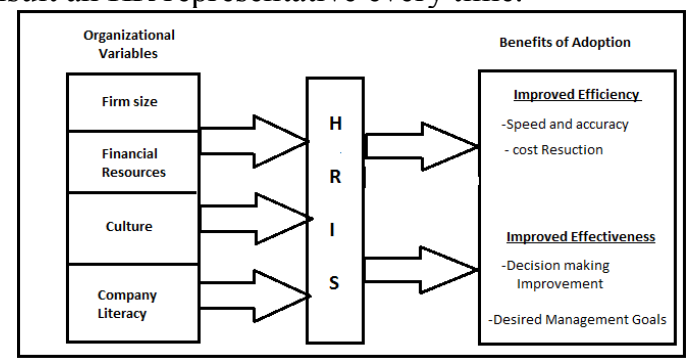

Figure 5

With an appropriate HRIS, Human Resources staff enables employees to do their own benefits updates and address changes, thus freeing HR staff for more strategic functions. Additionally, data necessary for employee management, knowledge development, career growth and development, and equal treatment is facilitated. 
Finally, managers can access the information they need to legally, ethically, and effectively support the success of their reporting employees. Specific benefits of such systems include:

- Faster information process

- Greater information accuracy

- Improved planning and program development

- Enhanced employee communications

- Reduction in cost of stored data in HR

- More transparency in the system

- More meaningful career planning \& counseling at all levels.

- Better ability to respond to environmental changes.

\section{Security Of HRIS}

The privacy of employee information has become a major issue in recent years. With identity theft becoming a common problem, employees are becoming more sensitive about who sees their personal information, and the security it is kept in. By making sure employee information that is kept in the HRIS is relevant to the company and making sure there is limited access (password protection) to such information, companies can make its employees more secure with the safety of their information. Whether electronic or paper, employee files deserve to be treated with great care. Establishing security and end-user privileges calls for a balance of incorporating, HR policy, system knowledge and day-to-day operations.

\section{Limitation Of HRIS}

An HRIS also can be a problematic for small businesses in which some employees must wear many hats. Some of the disadvantages of an HRIS involve human error during information input, costly technology to update in system and malfunctions or insufficient applications to support companies human resources needs. There is a demand for computer and technology specialists with general information technology knowledge, and finding a qualified specialist with human resources functional area knowledge can be difficult. With such a demand, companies cost to hire an HRIS specialist may be far above the average salary for a computer technology specialist.

\section{Conclusion}

Human resources information systems (HRIS) can play an important part in a company's HR function. After all, we live, work and play in the information age. Implementing an effective HRIS can be sure-fire for HR to stay on the cutting edge in its bid to deliver more effective and streamlined service. The main conclusion of this paper is the realization that the use of computerized HRIS is most effective then manual because its help to maintain data with more accuracy in less time. And that it also trues that HRIS functions improve HRM in terms of administrative purposes and analytical purposes. HRIS work as a key component of the organization and a good HRIS will provide important information about human resources needs and capabilities; this information will assist the management team in establishing the organizational mission and setting goals and objectives in motion. HRIS is not limited to the computer hardware and software applications that comprise the technical part of the system: it also includes the people, policies, procedures and data required to manage the HR function.

\section{References}

[1]. http://www.studymode.com/essays/The-Role-Of-Human-Resource-Information-435591.html

[2]. http://www.businessdictionary.com/definition/Human-Resource-Information-Systems-HRIS.html\#ixzz2geQaKtsy

[3]. http://www.dresserassociates.com/blog/what-is-a-hris/

[4]. http://www.hrpayrollsystems.net/hris/

[5]. http://en.wikipedia.org/wiki/Human resource management_system

[6]. http://www.hrpayrollsystems.net/hris-system-impact-to-companies/

[7]. http://www.slideshare.net/kumaravinash23/hris-1979388

[8]. http://www.scribd.com/doc/26766834/Human-Resource-Information-System

[9]. http://www.comparehris.com/Human-Resource-Information-Systems-/

[10]. http://www.sagepub.com/upm-data/25450_Ch1.pdf

[11]. http://www.siop.org/tip/backissues/tipjan98/may.aspx

[12]. http://srmo.sagepub.com/view/the-human-resources-program-evaluation-handbook/n23.xml

[13]. B. Pattanayak, Human Resource Management(PHI Learning Private Limited,2009).

[14]. L.M. Prasad, Human Resource Management (Sultan Chand \& Sons: Educational Publishers, 2006).

[15]. H John Bernardin, Human Resource Management (Tata McGraw-Hill Publishing Company Limited, 2007)

[16]. P.C. Tripathi, Human Resource Development (Sultan Chand \& Sons: Educational Publishers, 2006)

[17]. V S P Rao, Human resource Management (Excel Books, Second Edition, 2010)

[18]. Mohan Thite, Michael J. Kavanagh, Evolution of Human Resource Management and Human Resource Information Systems 
[19]. Development of HR Information System for an aerospace industry, SASTECH Journal, Volume 10, Issue 1, May 2011

[20]. Dr. Shikha N. Khera1, Ms. Karishma Gulati, Human Resource Information System and its impact on Human Resource Planning: A perceptual analysis of Information Technology companies, IOSR Journal of Business and Management (IOSRJBM) ISSN: 2278487X Volume 3, Issue 6 (Sep,-Oct. 2012)

[21]. Akansha Chauhan, Sanjeev Kr Sharma \& Tarun Tyagi, Role of HRIS in Improving Modern HR Operations, Journal Review of Management, Vol. 1, No. 2, April-June 2011

[22]. Kristine Dery, David Grant and Sharna Wiblen, Human Resource Information System (HRIS): Replacing or Enhancing HRM, Work and Organisational Studies The Institute Building (H03) The University of Sydney NSW 2006, Australia

[23]. Yasemin Bal, Serdar Bozkurt and Esin Ertemsir, The Importance of using Human Resource Information System (HRIS) and Research on Determining the success of HRIS, Management Knowledge and learning , International Conference 2012

[24]. Udani Chathurika Wickramaratna, Project report on The role of Human Resource Information System in Human Resource Planning in Private sector organization in Srilanka, Faculty of Graduate studies University of Colombo 28 February 2011 